NOTE

\title{
Isolation of a novel adenovirus from California sea lions Zalophus californianus
}

\author{
T. Goldstein ${ }^{1, *}$, K. M. Colegrove ${ }^{2}$, M. Hanson ${ }^{3}$, F. M. D. Gulland ${ }^{4}$ \\ ${ }^{1}$ Wildlife Health Center, School of Veterinary Medicine, University of California, Davis, California 95616, USA \\ ${ }^{2}$ Zoological Pathology Program, College of Veterinary Medicine, University of Illinois LUMC, Maywood, Illinois 60153, USA \\ ${ }^{3}$ Department of Veterinary Pathology, Armed Forces Institute of Pathology, Washington, DC 20306-6000, USA \\ ${ }^{4}$ The Marine Mammal Center, Marin Headlands, Ft. Cronkhite, Sausalito, California 94965, USA
}

\begin{abstract}
Viral hepatitis associated with adenoviral infection has been reported in California sea lions Zalophus californianus admitted to rehabilitation centers along the California coast since the 1970s. Canine adenovirus 1 (CAdV-1) causes viral hepatitis in dogs and infects a number of wildlife species. Attempts to isolate the virus from previous sea lion hepatitis cases were unsuccessful, but as the hepatitis had morphologic features resembling canine infectious hepatitis, and since the virus has a wide host range, it was thought that perhaps the etiologic agent was CAdV-1. Here, we identify a novel adenovirus in 2 stranded California sea lions and associate the infection with viral hepatitis and endothelial cell infection. Phylogenetic analysis confirmed the classification of the sea lion adenovirus in the Mastadenovirus genus with the most similarity to tree shrew adenovirus 1 (TSAdV-1, $77 \%$ ). However, as the sea lion adenovirus appeared to be equally distant from the other Mastadenovirus species based on phylogenetic analysis, results indicate that it represents an independent lineage and species. Although sequences from this novel virus, otarine adenovirus 1 (OtAdV-1), show some similarity to CAdV-1 and 2, it is clearly distinct and likely the cause of the viral hepatitis in the stranded California sea lions.
\end{abstract}

KEY WORDS: California sea lion · Zalophus californianus · Adenovirus • Viral hepatitis . Corneal edema

\section{INTRODUCTION}

Members of the adenovirus family Adenoviridae have been found in almost all vertebrate groups, and the genus Mastadenovirus comprises viruses from mammals (Benkö et al. 2005). Most adenoviruses are host-species specific, but some, such as canine adenovirus (CAdV) 1, have a wide host range and have been found to infect a number of wildlife species including foxes, wolves, raccoons, skunks, and bears (Woods 2001). Viral hepatitis associated with adenoviral infection has been documented in free-ranging California sea lions Zalophus californianus admitted to rehabilita- tion centers along the California coast (Britt et al. 1979, Dierauf et al. 1981). Viral inclusions and adenoviruslike virions were seen in lesions on light and electron microscopy, respectively. Virus isolation attempts were unsuccessful, and further identification of the virus was not pursued. As the viral hepatitis seen in the sea lions had morphologic features resembling canine infectious hepatitis, including multiple foci of necrosis, numerous virions within the nucleus, and the accumulation of lipid droplets within hepatocytes, and as their family, Otariidae, is closely related to bears, another species susceptible to $\mathrm{CAdV}$, it was thought that perhaps the etiology was the same. 
Adenoviruses have been isolated from gastrointestinal samples of other marine mammals including a sei whale Balaenoptera borealis from the Antarctic, 2 bowhead whales Balaena mysticetus harvested in Alaska, and a beluga whale Delphinapterus leucas from the St. Lawrence Estuary (Smith \& Skilling 1979, Smith et al. 1987, De Guise et al. 1995). As many adenoviruses can be isolated from normal tissues (especially endothelium and epithelium of the respiratory and gastrointestinal tracts, liver, and conjunctiva) and can cause a wide range of diseases (Russell \& Benkö 1999), the role of the whale adenoviruses remains to be determined. Although adenoviral infections are highly contagious, they are often nonfatal; generalized disease can, however, develop in immunocompromised or otherwise diseased individuals (Russell \& Benkö 1999). Adenoviral associated lesions have been observed sporadically in stranded California sea lions since first being described; however, a specific virus has not been identified in these cases. Here we identify a novel adenovirus as an etiologic agent associated with viral hepatitis and endothelial cell infections in California sea lions dying along the central California coast.

\section{MATERIALS AND METHODS}

Animals and samples. The presence of adenoviral DNA was examined in tissue samples from 2 live stranded California sea lions that died following admission to The Marine Mammal Center, a rehabilitation facility, on the central California coast. Case 1 (CSL 5680), a yearling male, stranded and died in 2003 with severe arteritis, interstitial pneumonia and pulmonary hemorrhage associated with metastrongyle lungworm infection (Kelly et al. 2005). Eosinophilic intranuclear inclusion bodies suggestive of an adenovirus infection were found within the endothelium of blood vessels of several organs including lung, mediastinal lymph node, spleen, and eye. Case 2 (CSL 7630) also a male yearling, stranded and died in 2008. Cause of death was a severe necrotizing viral hepatitis with intranuclear eosinophilic inclusions within hepatocytes. Tissues from both cases (mediastinal lymph node: CSL 1; liver: CSL 2) were submitted for thin section electron microscopy to further characterize the virus. Tissue sections were deparaffinized, hydrated, and post-fixed in $1 \%$ osmium tetroxide, then dehydrated, cleared, and embedded in epoxy resin. Thin sections (80 to $90 \mathrm{~nm}$ ) were cut and stained with uranyl acetate and lead citrate for electron microscopy. Formalin-fixed paraffin-embedded lung tissue from Case 1 (CSL 5680) and frozen liver from Case 2 (CSL 7630) were tested for the presence of adenoviral DNA by PCR. Serum samples were tested by serum neutral- ization for the presence of antibodies to CAdV-1 and 2 at the Cornell Diagnostic Laboratory (College of Veterinary Medicine, Cornell University). Testing was performed starting with the minimum serum dilution of $1: 4$, and samples with an antibody titer greater than 1:8 (i.e. the reciprocal of the highest dilution of the serum that neutralized infectivity of the virus) were considered positive. Samples with a titer $<8$ indicated no detectable antibodies.

Molecular analysis. DNA was extracted from the formalin-fixed paraffin-embedded lung tissue from Case 1 (CSL 5680) and frozen liver from Case 2 (CSL 7630) using the QIAamp DNA FFPE ${ }^{\circledR}$ and DNEasy ${ }^{\circledR}$ Tissue Kits respectively (Qiagen). Primers to detect and differentiate between CAdV-1 and 2 (Hu et al. 2001) and consensus primers to amplify a 324 bp fragment of the DNA polymerase gene of novel adenoviruses (Wellehan et al. 2004) were used. Parallel reactions amplifying a fragment of the mammalian ferritin gene were performed to control for the PCR amplificability of the DNA sample. Products of the expected size were cloned (pCR4-TOPO vector; Invitrogen) and sequenced using the 3730 DNA Analyzer (Applied Biosystems). Specific primers (sense: 5'-GCG CAC TTA CTC ATC CAT TTC C-3', antisense: 5'-GCT ATT TCT CCA CGC AGC GG-3') were designed and used in combination with the consensus primer pair to obtain additional sequence of the novel sea lion adenovirus DNA polymerase gene.

Raw sequences were edited and translated with Geneious Pro (version 5.1.4; Biomatters) (Drummond et al. 2010), and the identity of the viral DNA fragments were verified with the use of the BLASTn program run on the non-redundant National Center for Biotechnology Information (NCBI) database (http:// blast.ncbi.nlm.nih.gov/Blast.cgi). Prior to analysis, the degenerate primers sequences were removed, and the predicted 168 amino acid sequence from the novel adenovirus was aligned with amino acid sequences from 23 known adenoviruses using Clustal W (Larkin et al. 2007).

Phylogenetic tree reconstructions were performed with programs of the PHYLIP package (Phylogeny Inference Package version 3.68, University of Washington; Felsenstein 1989). For distance matrix analysis, the aligned amino acid sequences were processed first with Protdist (Dayhoff PAM 001 matrix) and then with Fitch (global rearrangements). For bootstrap analysis, Seqboot was run (1000 samplings) prior to Protdist and Fitch, and finally Consense was applied (Harrach \& Benkö 2007). The resulting phylogenetic trees were visualized in TreeView (Page 1996).

Virus isolation. Liver tissue from CSL 2 that had been snap frozen and stored at $-70^{\circ} \mathrm{C}$ was homogenized using a Dounce homogenizer in $500 \mathrm{ml}$ phos- 
phate-buffered saline PBS containing $500 \mathrm{IU} \mathrm{ml}^{-1}$ penicillin and $500 \mathrm{mg} \mathrm{ml}^{-1}$ streptomycin. The homogenate was filtered with a $0.45 \mathrm{~mm}$ filter (Nalgene; Nalge Company) and inoculated onto monolayers of MadinDarby canine kidney cells (MDCK; American Type Culture Collection [ATCC]) and early-passage California sea lion kidney fibroblast cell lines (obtained from the Wise Laboratory of Environmental and Genetic Toxicology, University of Southern Maine). MDCK cells were maintained in Eagle's minimum essential media (MEM) supplemented with $10 \%$ fetal calf serum, $2 \mathrm{mM}$ L-glutamine (Gibco, Invitrogen), $0.1 \mathrm{mM}$ sodium pyruvate (Gibco, Invitrogen), $100 \mathrm{IU} \mathrm{ml}^{-1}$ penicillin, and $100 \mu \mathrm{g} \mathrm{ml}^{-1}$ streptomycin (Gibco, Invitrogen), $0.1 \%$ gentamicin (Gibco, Invitrogen). The sea lion fibroblast cell line was maintained in complete Dulbecco MEM (DMEM)-F12 (Gibco, Invitrogen) supplemented with $15 \%$ fetal calf serum (FCS; Atlanta Biologicals), $2 \mathrm{mM}$ L-glutamine (Gibco, Invitrogen), $0.1 \mathrm{mM}$ sodium pyruvate (Gibco, Invitrogen), $100 \mathrm{IU}$ $\mathrm{ml}^{-1}$ penicillin, and $100 \mu \mathrm{g} \mathrm{ml}^{-1}$ streptomycin (Gibco, Invitrogen). Prior to inoculation, cells were washed with PBS, then inoculated with $500 \mu \mathrm{l}$ of liver homogenate, incubated at $37^{\circ} \mathrm{C}$, and rocked every $10 \mathrm{~min}$ for $1 \mathrm{~h}$. Complete DMEM-F12 supplemented with 5\% FCS and complete MEM supplemented with $2 \%$ FCS were then added to the sea lion and MDCK cells, respectively, and the cultures were incubated and monitored daily for cytopathic effect (CPE). For passaging, the cells were harvested using a scraper, the cell suspension freeze-thawed 3 times at $-70^{\circ} \mathrm{C}$, and used to inoculate the cells. The inoculated cell culture was submitted for electron microscopy to the California Animal Health and Food Safety Laboratory System (University of California Davis). The supernatant was concentrated in an ultracentrifuge and then examined directly by negative stain electron microscopy. DNA was also extracted from both the inoculated MDCK and sea lion cell cultures using the DNEasy ${ }^{\circledR}$ Tissue Kit (Qiagen) and tested by PCR with the specific primers described in 'Molecular analysis' to detect a fragment of the novel sea lion adenoviral DNA polymerase gene. Products of the expected size were cloned and sequenced as described in 'Molecular analysis'.

\section{RESULTS}

Although the cause of death in CSL 1 was attributed to arteritis associated with a severe Otostrongylus circumlitus infection, intranuclear inclusions were observed in several tissues, including the lung, mediastinal lymph node, spleen, and eye. In the lung, inclusions were noted within the endothelial nuclei of inflamed arteries and arterioles (Fig. 1). In the right

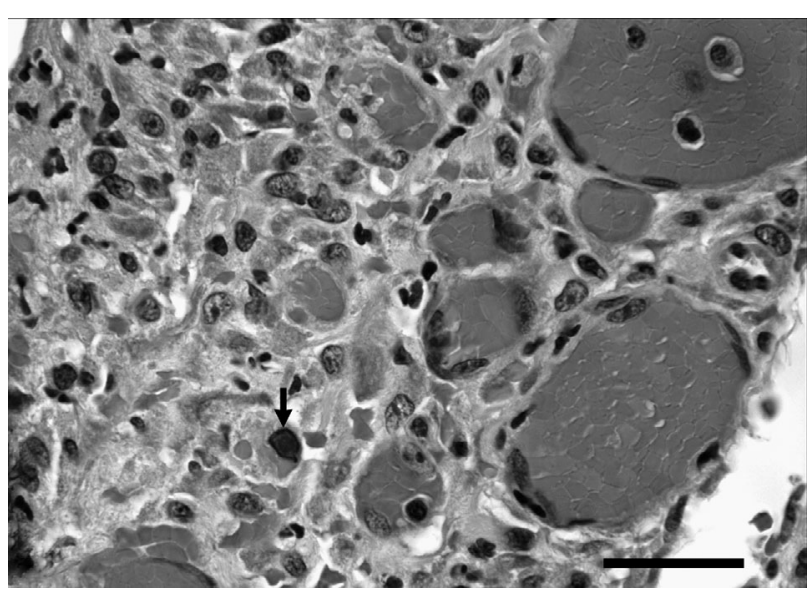

Fig. 1. Zalophus californianus. Histologic section of a region of pulmonary arteritis in a California sea lion. An enlarged endothelial cell nucleus contains a smudgy inclusion body (arrow). H\&E staining. Scale bar $=50 \mu \mathrm{m}$

eye, rare endothelial cells within the cornea, conjunctiva, and ciliary body contained intranuclear inclusions. There was moderate ulcerative keratitis, corneal edema, iridocyclitis, and conjunctivitis. Significant gross lesions found upon necropsy of CSL 2 were a pale, friable liver and pale kidneys. Histologically, there was a viral hepatitis characterized by multifocal random necrosis with intranuclear inclusion bodies. Ultrastructural examination of mediastinal lymph node (CSL 1) and liver (CSL 2) revealed numerous 70 to $90 \mathrm{~nm}$ icosohedral, adenoviral-like particles within the nucleus of affected endothelial cells (Fig. 2A). Sera from both sea lions were negative (titer of 1:4) for antibodies against both CAdV-1 and 2 .

PCR to detect CAdV-1 and 2 was negative. An amplicon of the correct size (324 bp) was amplified using the consensus nested-PCR method. Sequencing confirmed the presence of a fragment of the DNA polymerase gene of a novel adenovirus. A larger fragment (508 bp, GenBank accession no. GU979536) of the DNA polymerase gene was obtained using the 2 primer pairs in combination and was used for further phylogenetic analysis. Comparison of the sequence to known adenoviruses in GenBank indicated that this was a novel virus belonging to the Mastadenovirus genus. After translating the nucleotide sequences to the predicated amino acid sequence, comparisons showed that the virus had most similarity to tree shrew adenovirus 1 (TSAdV-1, 77\%). Analyses also indicated that although the novel virus was not identical to either adenovirus found in dogs, it did have some similarity to CAdV-1 (72\%) and $2(74 \%)$, respectively. An alignment of the predicted homologous sequences is shown (Fig. 3). Phylogenetic analysis confirmed the classification of the sea lion adenovirus in the Mastadenovirus 


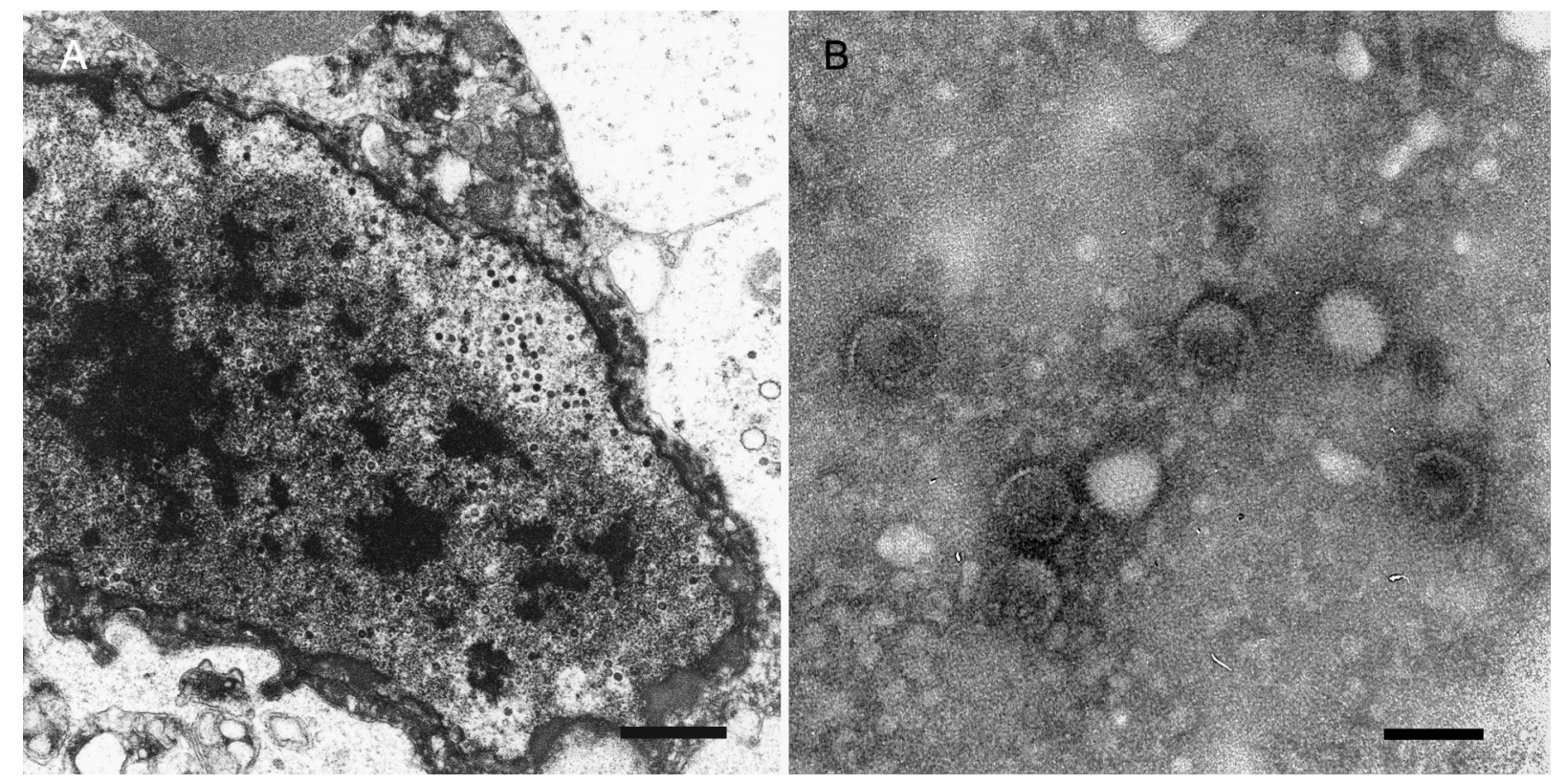

Fig. 2. Zalophus californianus. (A) Transmission electron microscopy of adenoviral infection in a sea lion lymph node (CSL 1) with 70-90 nm icosohedral adenoviral-like particles in the nucleus of an endothelial cell. Scale bar $=3.5 \mu \mathrm{m}$. (B) Supernatant from infected sea lion kidney fibroblast cells in culture showing naked icosohedral virions consistent with an adenovirus. Scale bar $=100 \mathrm{~nm}$
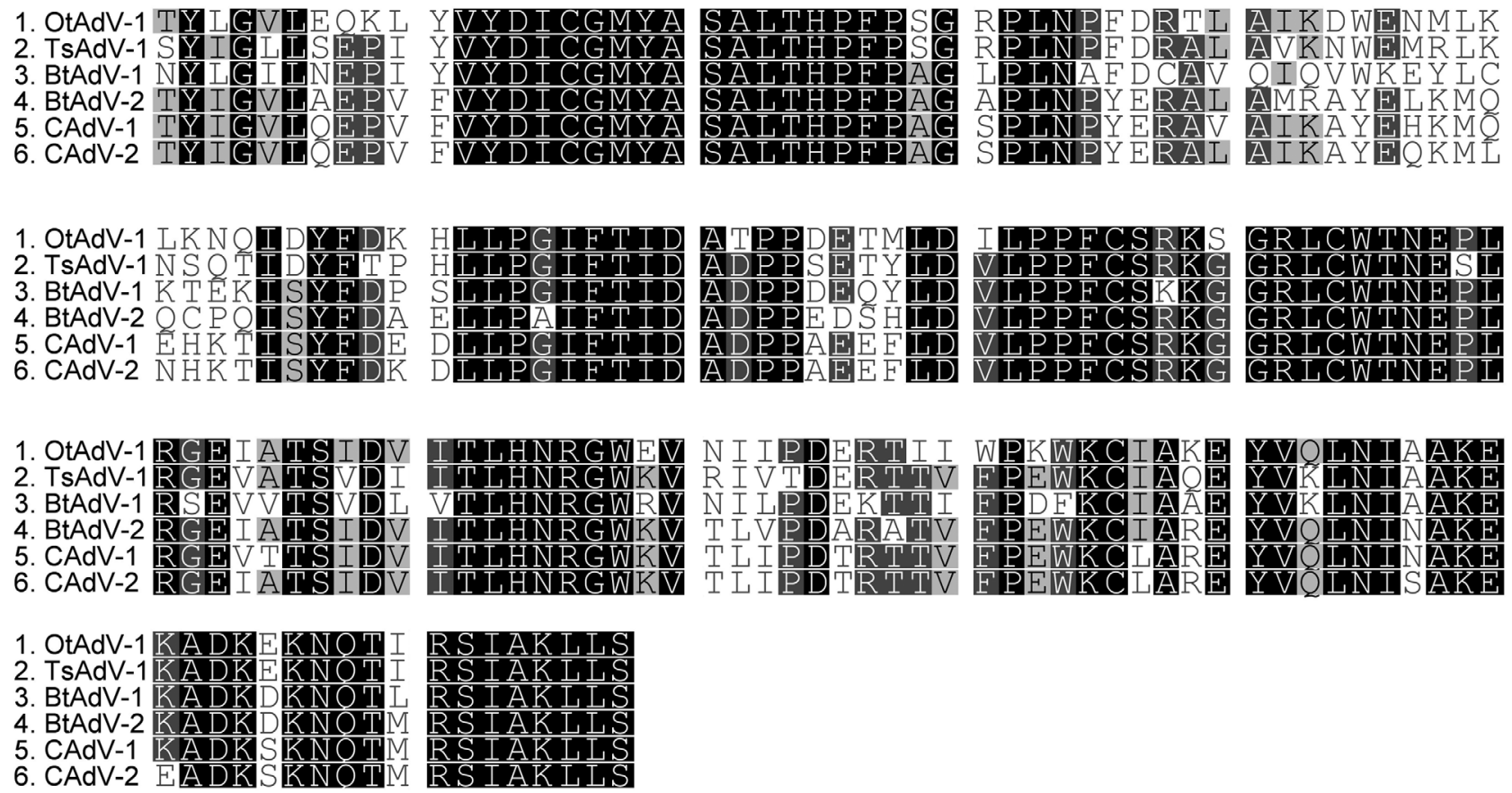

Fig. 3. Alignment of the predicted 168 amino acid sequence of the novel sea lion adenovirus DNA polymerase gene fragment with the corresponding regions from tree shrew adenovirus (TSAdV-1, GenBank accession no. AAN84890), bat adenovirus 1 (BtAdv1, GenBank accession no. AB303301) and 2 (BtAdV-2, GenBank accession no. FJ983127), and canine adenovirus 1 (CAdV-1, GenBank accession no. AAB05434) and 2 (CAdV-2, GenBank accession no. U77082). Identical amino acids are highlighted in black, those in dark grey have $80-100 \%$ similarity, light grey $60-80 \%$ similarity, and those in white have $<60 \%$ similarity. The alignment was produced using Clustal W (Larkin et al. 2007) using the Geneious Pro software (version 5.1.4; Biomatters) 


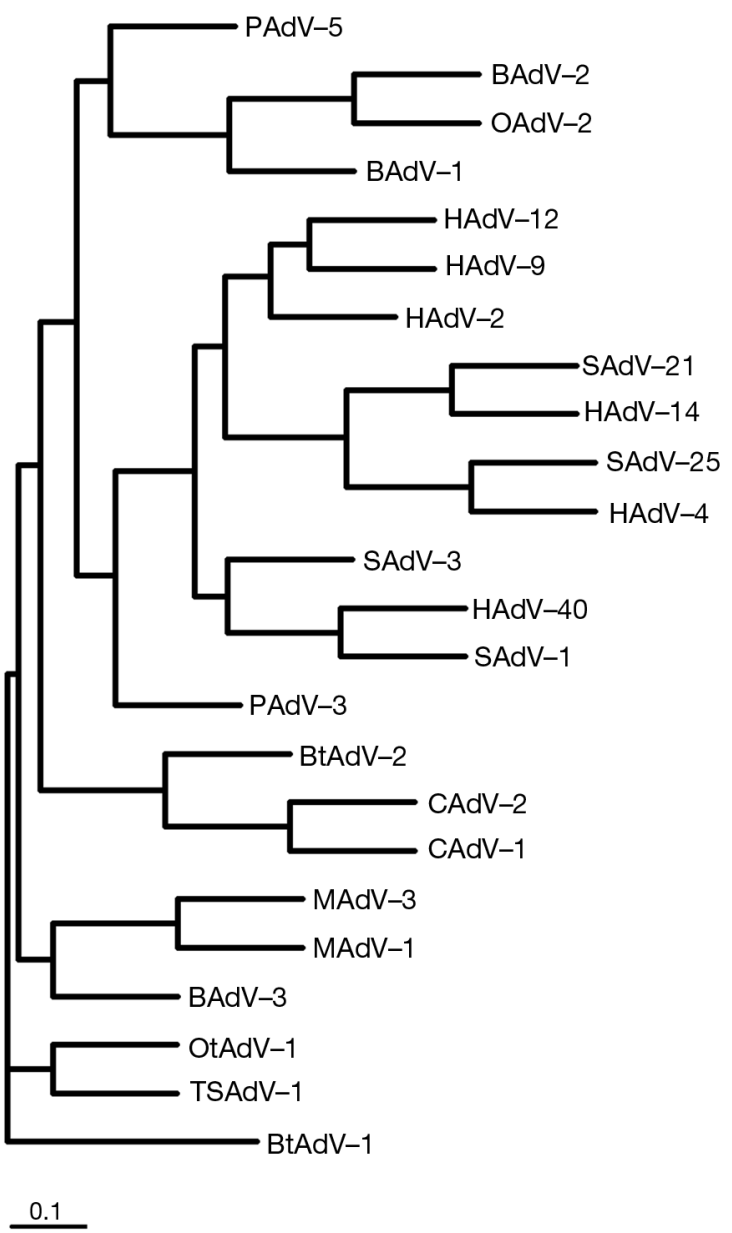

Fig. 4. Phylogenetic tree constructed by distance matrix analysis (1000 replicates) of the 168 amino acid sequence alignments of the DNA polymerase gene fragment comparing the novel sea lion adenovirus (OtAdV-1) to other viruses in the Mastadenovirus genus produced using Phylip (Phylogeny Inference Package version 3.68, University of Washington, Seattle, WA, USA). Scale bar indicates an evolutionary distance of 0.1 amino acid substitution per position in the sequence. Other sequences were retrieved from GenBank, host abbreviations: TS: tree shrew; Bt: bat; C: canine; B: bovine; P: porcine; O: ovine; H: human; S: simian; M: murine

genus and indicated that its immediate neighbours included TsAdV-1, bat adenovirus 1 (BtAdv-1), and bovine adenovirus 3 (BAdV-3) (Fig. 4). Other related viruses may include the murine adenoviruses, BtAdV2 , and the canine adenoviruses; however, as the sea lion adenovirus appeared to be equally distant from the other Mastadenovirus species, results suggest it represents an independent lineage and species.

After one passage, the sea lion cell culture monolayer inoculated with liver homogenate from CSL 2 exhibited a cytopathic effect, characterized by clusters of rounded enlarged cells, seen within $4 \mathrm{~d}$ of inocula- tion. Direct negative staining electron microscopy revealed 70 to $75 \mathrm{~nm}$ icosohedral, adenoviral-like particles within the cell culture supernatant (Fig. 2B). No cytopathic effect was exhibited in the MDCK monolayers inoculated with the liver tissue homogenate from CSL 2. PCR analysis of DNA extracted from both the sea lion and MDCK cell cultures was positive and amplified the $508 \mathrm{bp}$ fragment of the adenoviral DNA polymerase gene. Although no cytopathic effect was evident in the MDCK cell culture, and electron microscopy did not reveal viral particles, PCR and sequencing confirmed the presence of the novel California sea lion adenoviral sequence in both cell cultures.

\section{DISCUSSION AND CONCLUSIONS}

These 2 cases identify a novel adenovirus in California sea lions that is associated with a hepatitis and endothelial cell infection in multiple tissues. Although this novel virus shows some similarity to CAdV-1 and 2 , it is clearly molecularly distinct, as also confirmed by the negative CAdV serology. We propose that this virus be named otarine adenovirus 1 (OtAdV-1) according to the convention for naming of adenoviruses. The acute necrotizing hepatitis seen in CSL 2 was consistent with lesions in other sea lions described by Britt et al. (1979) and Dierauf et al. (1981), and which had features consistent with infectious canine hepatitis. Although previous cell culture attempts using MDCK cells were unsuccessful, these previous cases could have resulted from the same novel adenovirus reported here. The successful isolation and visualization of viral particles of this virus using sea lion cell lines highlights the need for species-specific cell lines in wildlife disease research. However, PCR can be applied successfully even in the lack of such cell cultures.

Adenoviruses cause a wide range of lesions in other species, and this feature was also seen in these cases. Although CSL 1 died as a result of a metastrongyloid nematode infection, adenoviral inclusions were found in multiple tissues. The concurrent adenoviral infection may have contributed to the severity of the parasitic infection and thus death. Alternatively, it is possible that the lesions were associated with recrudescence of a persistent virus infection, another common feature of adenoviral infections (Benkö 2008). Thus, the characteristics of this virus as a primary pathogen are unclear and require further study. In domestic species, experimental studies are often performed to determine whether a virus has the characteristics of being a primary pathogen. It is not possible to perform this type of experimental work on marine mammal species in the United States due to permit 
constraints; however, the widespread cytopathic effect evident in the inoculated sea lion cell culture indicated that the virus may have the ability to be the primary pathogen and cause of mortality in some individuals. Further work to examine for the presence of viral DNA in healthy individuals or those that died due to other causes is needed to determine whether the virus can be acquired without resulting in associated lesions.

The ocular lesions seen in CSL 1 were very similar to lesions seen in approximately $20 \%$ of dogs naturally infected with CAdV-1 (Greene 1990). In infected dogs, viremia results in dissemination of the virus to many tissues including the eye, liver, kidney, and other endothelium. Within the liver, infection can result in hepatic necrosis and hepatitis in animals with low antibody titers or inapparent disease in animals with sufficient antibody titers. In the eye, viremia results in initial endothelial damage and anterior uveitis, and corneal edema develop with increasing antibody titers (Greene 1990). In the 2 sea lions with adenoviral infection, a similar pathogenesis may have been present, such that the differences in the lesions noted may be related to antibody titers at the time of infection. Corneal opacities are seen frequently in captive, stranded, and free-ranging California sea lions (Gulland et al. 2001), and the etiology of these lesions is often undiagnosed. The possible association of this sea lion adenovirus in cases with keratoconjunctivitis and corneal edema, features common in adenoviral ocular infections in other species (Rajaiya \& Chodosh 2006), should be considered among the differential diagnoses in pinnipeds with ocular disease. Thus, further studies are needed to investigate the prevalence of this viral infection in California sea lions and to determine its role as a primary pathogen in individuals with liver and or ocular lesions.

Acknowledgements. This work was supported through funds from NOAA Fisheries Protected Resources Program Office Grant No. NA07NMF4390343. We thank the staff and volunteers of The Marine Mammal Center, especially Elizabeth Wheeler and Heather Harris, for performing the necropsies and sample collection; Brett Smith from the Marine Ecosystem Diagnostic and Surveillance Laboratory, University of California Davis for molecular analysis; Bob Nordhausen from the California Animal Health and Food Safety Laboratory System for performing electron microscopy; and Henry Jenkins at the Armed Forces Institute of Pathology for photomicrography.

\section{LITERATURE CITED}

Benkö M (2008) Adenoviruses: pathogenesis. In: Mahy BWJ, van Regenmortel MHV (eds) Encyclopedia of virology, 3rd edn. Elsevier, Oxford, p 24-29

Editorial responsibility: Michael Moore, Woods Hole, Massachusetts, USA
Benkö M, Harrach B, Both GW, Russell WC and others (2005) Family Adenoviridae. In: Fauquet CM, Mayo MA, Maniloff J, Desselberger U, Ball LA (eds) Virus taxonomy. 8th Report of the International Committee on Taxonomy of Viruses. Elsevier, New York, NY, p 213-228

Britt JO Jr., Nagy AZ, Howard EB (1979) Acute viral hepatitis in California sea lions. J Am Vet Med Assoc 175:921-923

De Guise S, Lagac A, Bfland P, Girard C, Higgins R (1995) Non-neoplastic lesions in beluga whales (Delphinapterus leucas) and other marine mammals from the St. Lawrence Estuary. J Comp Pathol 112:257-271

Dierauf LA, Lowenstine LJ, Jerome C (1981) Viral hepatitis (adenovirus) in a California sea lion. J Am Vet Med Assoc 179:1194-1197

Drummond AJ, Ashton B, Buxton S, Cheung M and others (2010) Geneious v 5.1. Available at www.geneious.com

Felsenstein J (1989) PHYLIP — Phylogenetic inference package (version 3.5). Cladistics 5:164-166

Greene CE (1990) Infectious canine hepatitis and canine acidophil cell hepatitis. In: Greene CE (ed) Infectious diseases of the dog and cat, 2nd edn. WB Saunders, Philadelphia, PA, p 22-27

Gulland FMD, Haulena M, Dierauf LA (2001) Seals and sea lions. In: Dierauf LA, Gulland FMD (eds) Handbook of marine mammal medicine. CRC Press, Boca Raton, FL, p $907-922$

Harrach B, Benkö M (2007) Phylogenetic analysis of adenovirus sequences. In: Wold WSM, Tollefson AE (eds) Adenovirus methods and protocols, 2nd edn, Vol 2: Ad proteins, RNA, lifecycle, host interactions, and phylogenetics. Methods Mol Med 13. Humana Press, Totowa, NJ, p 299-334

Hu RL, Huang G, Qiu W, Zhong ZH, Xia XZ, Yin Z (2001) Detection and differentiation of CAV-1 and CAV-2 by polymerase chain reaction. Vet Res Commun 25:77-84

> Kelly TR, Greig D, Colegrove KM, Lowenstine LJ, Murray Dailey M, Gulland FM, Haulena M (2005) Metastrongyloid nematode (Otostrongylus circumlitus) infection in a stranded California sea lion (Zalophus californianus) - a new host-parasite association. J Wildl Dis 41:593-598

> Larkin M, Blackshields G, Brown N, Chenna R and others (2007) Clustal W and Clustal X version 2.0. Bioinformatics 23:2947-2948

Page RD (1996) TreeView: an application to display phylogenetic trees on personal computers. Comput Appl Biosci 12:357-358

Rajaiya J, Chodosh J (2006) New paradigms in infectious eye disease: adenoviral keratoconjunctivitis. Arch Soc Esp Oftalmol 81:493-498

Russell WC, Benkö M (1999) Adenoviruses (Adenoviridae): Animal viruses. In: Webster RG, Granoff A (eds) Encyclopedia of virology. Academic Press, London, p 14-21

Smith AW, Skilling DE (1979) Virus and virus diseases of marine mammals. J Am Vet Med Assoc 175:918-920

> Smith AW, Skilling DE, Benirschke K, Albert TF, Barlough JE (1987) Serology and virology of the bowhead whale (Balaena mysticetus). J Wildl Dis 23:92-98

Wellehan JFX, Johnson AJ, Harrach B, Benkö M and others (2004) Detection and analysis of six lizard adenoviruses by consensus primer PCR provides further evidence of a reptilian origin for the Atadenoviruses. J Virol 78:13366-13369

Woods LM (2001) Adenoviral diseases. In: Williams ES, Barker I (eds) Infectious diseases of wild mammals, 3rd edn. Iowa State University Press, Ames, IA, p 202-213

Submitted: March 22, 2010; Accepted: December 13, 2010

Proofs received from author(s): March 27, 2011 